\title{
Influence of Pile Soil Interaction on Seismic Behavior of PHC Pipe Piles
}

\author{
Guilan Tao ${ }^{1, a}$, Qingquan Zhou ${ }^{1, b}$,Yuepeng Pan ${ }^{1, c}$ and Jie Chen ${ }^{1, d}$ \\ ${ }^{1}$ Hohai University, 1 Xikang Road, Nanjing, China \\ agltao@hhu.edu.cn, ${ }^{b}$ zqq920702@qq.com, ${ }^{\text {}} 562167074 @ q q . c o m,{ }^{d}$ 690675836@qq.com
}

\begin{abstract}
Keywords: PHC pipe pile; Soil-pile interaction; equivalent embedded method; $p-y$ curve method; seismic behavior

Abstract. To study the influence of pile-soil interaction on the seismic behavior of PHC piles, this paper takes the PHC pile in the soft clay as the research object, which is simulated by fiber beam element, and the pile-soil interaction is simulated by using equivalent embedded method and p-y soft clay soil spring which is under cyclic load, respectively. The seismic behavior index of pile foundation under limit state is obtained through applying the horizontal cyclic load on the pile top. The research shows that, with the different depth of pile, the hysteretic energy dissipation index and the displacement ductility factor obtained by the equivalent embedded model are about 2.2 2.5 times and 1.1 1.4 times of the p-y curve model respectively. While the yield strength and ultimate strength obtained by the p-y curve model are larger than those obtained by equivalent embedded method.
\end{abstract}

\section{Introduction}

As one of the most commonly used structure types in harbor engineering, the high-pile wharf mainly uses the piles embedded in the foundation to bear the horizontal and vertical load. In order to consider the characteristics of pile-soil interaction and simplify the calculation, the p-y curve method and the equivalent embedded method are used to simulate the pile-soil interaction effect according to Chinese standard for pile foundation of harbor engineering [1]. The equivalent embedded method assumes that the pile foundation is embedded at a certain depth under the mud surface. The pile below the embedded point is not considered in the calculation, which is similar to the rigid foundation in the building structure. In the p-y curve method, the pile-soil interaction is equivalent to a series of soil springs and the change of soil ultimate resistance with the depth of the soil and the nonlinear relationship between soil resistance and pile deflection can be taken into consideration, which has high precision while simulating the pile-soil interaction. Despite of the simplicity and convenience of equivalent embedded method in the engineering design, the calculation formula of the equivalent embedded point is based on the premise that only elastic deformation occurs in the pile foundation. When the deformation of the soil is large and plastic deformation occurs in the pile foundation, the seismic performance of pile foundation and the accuracy of calculating seismic performance indexes by using the equivalent embedded model to simulate the pile-soil interaction should be further studied.

Based on the needs of research on the seismic damage model of pile foundation considering pile-soil interaction, this paper compares and analyzes the seismic performance indexes of PHC pipe piles in the condition of ultimate damage under horizontal cyclic load by using equivalent embedded method and p-y curve method to simulate pile-soil interaction, respectively. Besides, the reasonable calculation method of seismic behavior of PHC pipe piles considering pile-soil interaction is also discussed.

\section{Finite element model}

Fiber beam element. The B21 beam element in ABAQUS is used to simulate PHC pipe piles and thick-walled pipes is selected as cross section form of beam element. The beam elements of the protective layer concrete and the core concrete are established by the common node method. According to the actual position of the prestressed steel bar, the keyword rebar is used to insert the steel bar into the core concrete part of the beam element section. The initial tensile stress is applied to 
the longitudinal reinforcement of the pipe piles through the keyword initial condition. Considering the prestress loss, the initial tensile stress of the prestressed steel bar is calculated according to the Chinese Standard "Pre-tensioned prestressed concrete pipe pile" (GB13476-2009) [2]. The UCONCRETE01 and USTEEL02 constitutive model in the pq-fiber subroutine [3] programmed by Tsinghua University is used as concrete and prestressed longitudinal reinforcement constitutive model, respectively. The fiber point partition of beam section and the layout of prestressed bar are shown in Figure 1.

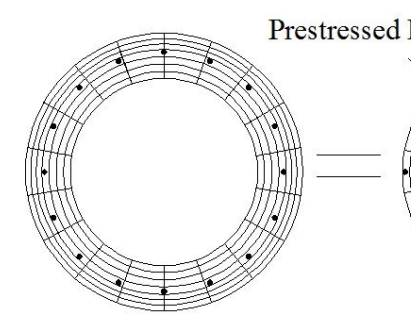

(a)

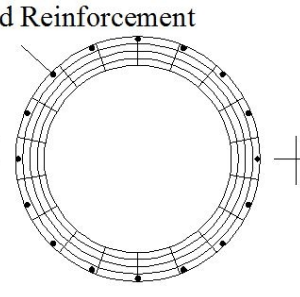

(b)

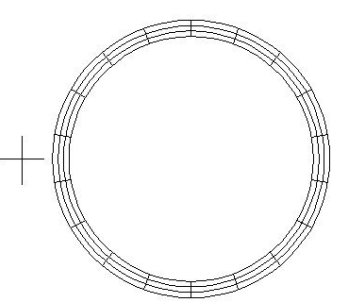

(c)

Fig.1. Fiber point partition graph of $\mathrm{PHC}$ pipe pile section, (a) PHC pipe pile; (b) concrete core; (c) protective layer concrete

Calculating model. The equivalent embedded method and the soft clay p-y soil spring under cyclic load are used to simulate the pile-soil interaction, respectively. The embedded depth of the pile foundation is calculated according to the literature [1] in the equivalent embedded method. The soil spring function is realized by the connection unit connector, which is arranged every $0.5 \mathrm{~m}$ below the mud surface. One end of the soil spring is connected with the pile body and the other is fixed. The specific parameters of soil spring are calculated according to method in the literature [4]. Considering the constraints of the pile cap on the pile top as well as the bearing layer on the pile bottom in the high pile wharf structure, the rotation degree of freedom of the pile top and the vertical degree of freedom of the pile bottom are constrained. Vertical axis force and horizontal displacement are loaded at the top of the pile to simulate the effect of axis pressure and horizontal seismic load, respectively. The finite element analysis models of PHC pipe piles with above two methods are shown in Figure 2 and 3 , respectively.

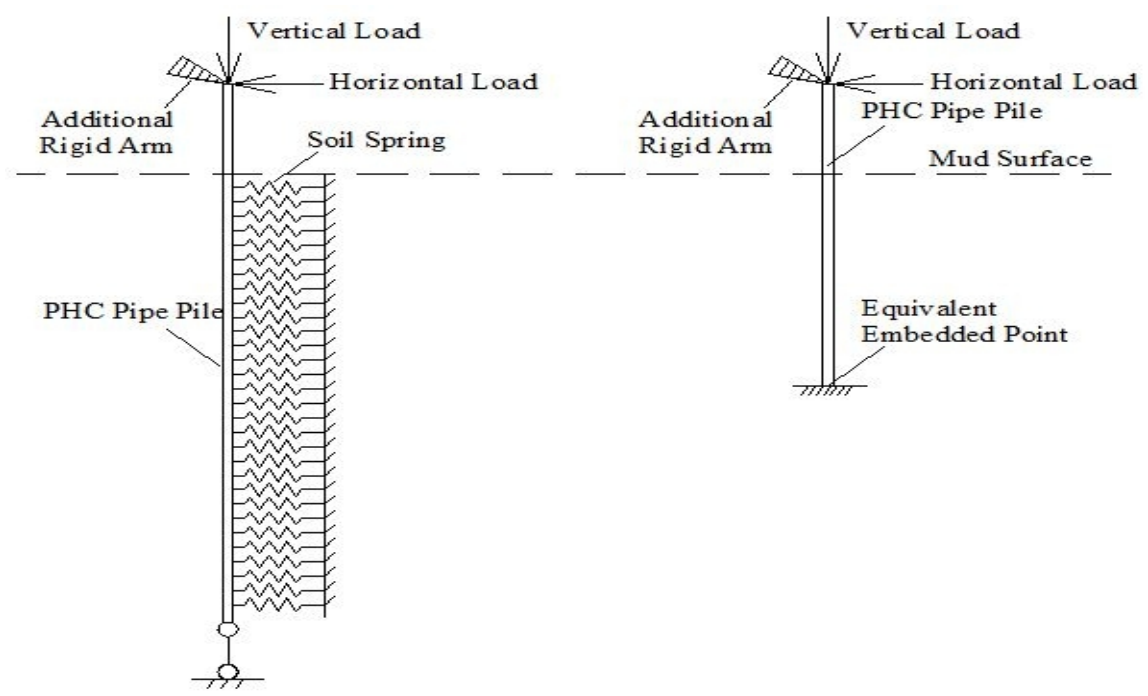

Fig.2. Calculating model of PHC pipe pile Fig.3. Calculating model of PHC pipe pile withp-y soil spring method with equivalent embedded method

The concrete strength grade of PHC pipe pile is C80. The grade 35 ductile and low relaxation spiral groove steel bars used in prestressed concrete are used as prestressed steel bar, with a tensile strength of not less than $1420 \mathrm{MPa}$, which are evenly arranged along pipe pile circumference. The elastic modulus $\mathrm{E}_{0}$, yield strength $\mathrm{f}_{\mathrm{y}}$ and hardening rigidity coefficient $\alpha$ of the prestressed steel bar is 200 $\mathrm{GPa}, 1420 \mathrm{MPa}$ and 0.001 , respectively. The relevant parameters of the protective layer and core 
concrete are calculated according to the rule of Literature [5]. The axial compressive strength $\mathrm{f}_{\mathrm{c} 0}$, peak compressive strain $\varepsilon_{\mathrm{c} 0}$ and ultimate compressive strain $\varepsilon_{\mathrm{cu}}$ of protective layer concrete are $50 \mathrm{MPa}$, 0.002 and 0.005 , respectively. The axial compressive strength $\mathrm{f}_{\mathrm{c} 0}$, peak compressive strain $\varepsilon_{\mathrm{c} 0}$, ultimate compressive strength $\mathrm{f}_{\mathrm{u}}$ and ultimate compressive strain $\varepsilon_{\mathrm{cu}}$ of core concrete are $55 \mathrm{MPa}$, $0.003,13 \mathrm{MPa}$ and 0.008 , respectively.

\section{Results and discussion}

Calculating parameters. The type C PHC pipe pile with diameter of $800 \mathrm{~mm}$ is taken as the research object [6], and the relevant parameters are shown in Table 1. The length of pile is $25 \mathrm{~m}$ and axial pressure ratio on pile top is 0.1 . The undrained shear strength of the soil is $20 \mathrm{kPa}$. The depth of the pile into the soil is $14 \mathrm{~m}, 17 \mathrm{~m}, 20 \mathrm{~m}$ and $23 \mathrm{~m}$, respectively.

Tab.1. The parameters of PHC pipe pile

\begin{tabular}{|c|c|c|c|c|c|c|c|c|c|}
\hline $\begin{array}{c}\text { Pile } \\
\text { Diameter } \\
(\mathrm{mm})\end{array}$ & $\begin{array}{l}\text { Pile } \\
\text { Type }\end{array}$ & $\begin{array}{c}\text { Wall } \\
\text { Thickness } \\
(\mathrm{mm})\end{array}$ & $\begin{array}{l}\text { Stirrup } \\
\text { Spacing } \\
(\mathrm{mm})\end{array}$ & $\begin{array}{c}\text { Stirrup } \\
\text { Diameter } \\
(\mathrm{mm})\end{array}$ & $\begin{array}{c}\text { Prestressed } \\
\text { Reinforcement }\end{array}$ & $\begin{array}{c}\text { Reinforcement } \\
\text { Ratio } \\
(\%)\end{array}$ & $\begin{array}{c}\text { The Diameter } \\
\text { of Prestressed } \\
\text { Reinforcement } \\
\text { (mm) }\end{array}$ & $\begin{array}{c}\text { Effective } \\
\text { Prestress } \\
\text { of Concrete } \\
(\mathrm{MPa})\end{array}$ & $\begin{array}{c}\text { Effective } \\
\text { Prestress } \\
\text { of } \\
\text { Reinforcement } \\
(\mathrm{MPa})\end{array}$ \\
\hline 800 & $\mathrm{C}$ & 130 & 80 & 6 & $32 \Phi 12.6$ & 1.46 & 690 & 11.1 & 761.22 \\
\hline
\end{tabular}

Loading mode. According to the provisions of the literature [7], the displacement loading system was adopted for the loading system in calculation. When the horizontal bearing capacity of the pile top under a certain displacement loading was less than $85 \%$ of the maximum horizontal bearing capacity of the pile top, the loading was stopped. In the calculation, the horizontal bearing capacity of the pile top corresponding to each displacement loading was obtained by extracting the horizontal force of the pile top.

The analysis of calculation results. According to different embedded depths of pile foundation, the load-displacement hysteretic relationship curves of pile top were obtained by using p-y curve method and equivalent embedded method respectively, as is shown from Figure 4 to figure 7. Figures from 4 to 7 show that the hysteretic curves obtained by p-y curve method and equivalent embedded method were both arcuate hysteretic curves, however, compared with that of p-y curve method, the pinching degree of the hysteretic curves of equivalent embedded method was relatively smaller and the shape was more full. The ultimate displacement of pile foundation was larger when the embedded depth of pile foundation was shallow, and with the deepening of the embedded depth, the difference between the two ultimate displacements was reduced.
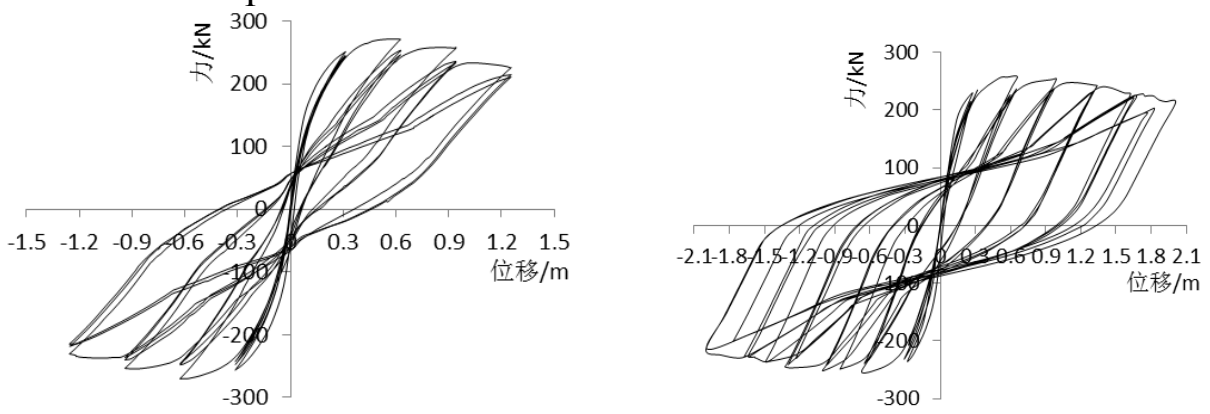

(a)hysteretic curve of p-y curve method (b)hysteretic curve of equivalent embedded method

Fig.4. Comparison of hysteresis curves of pile with embedded depth of $14 \mathrm{~m}$ 

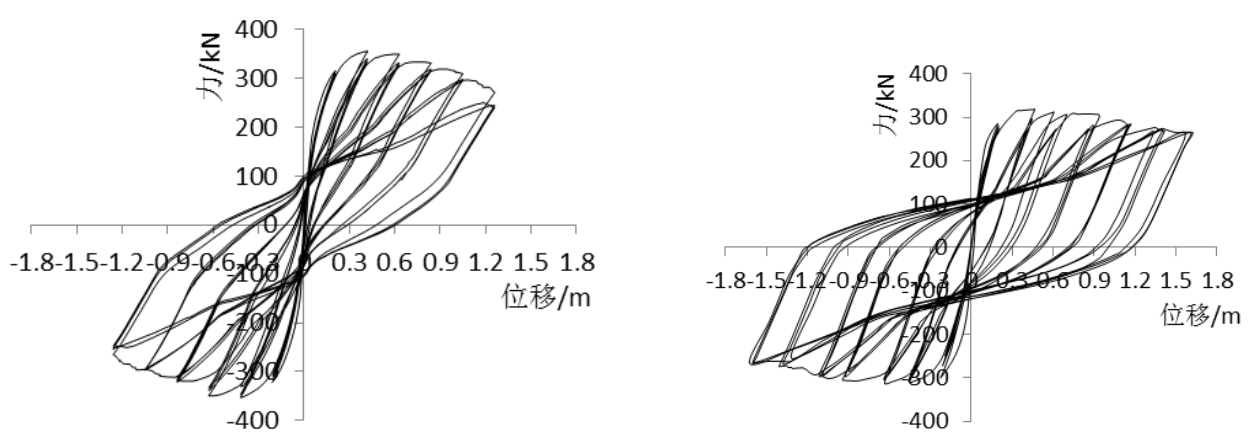

(a)hysteretic curve of p-y curve method (b)hysteretic curve of equivalent embedded method

Fig.5. Comparison of hysteresis curves of pile with embedded depth of $17 \mathrm{~m}$
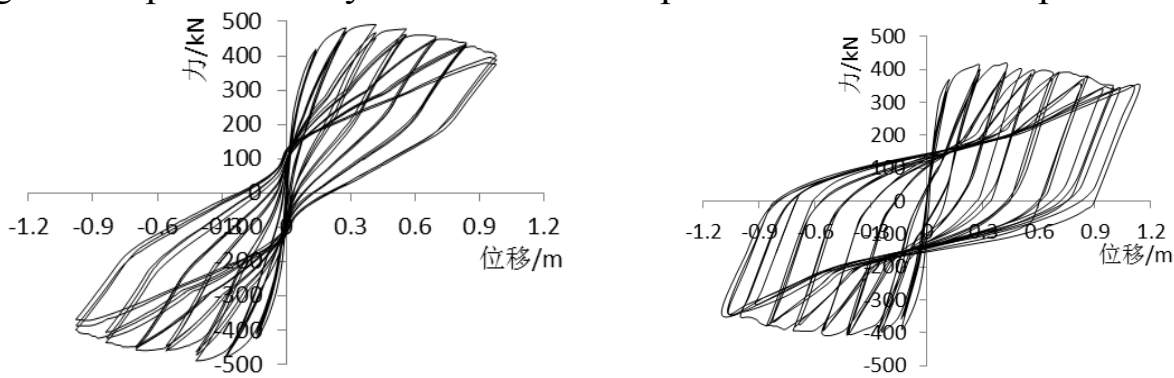

(a)hysteretic curve of p-y curve method (b)hysteretic curve of equivalent embedded method

Fig.6. Comparison of hysteresis curves of pile with embedded depth of $20 \mathrm{~m}$
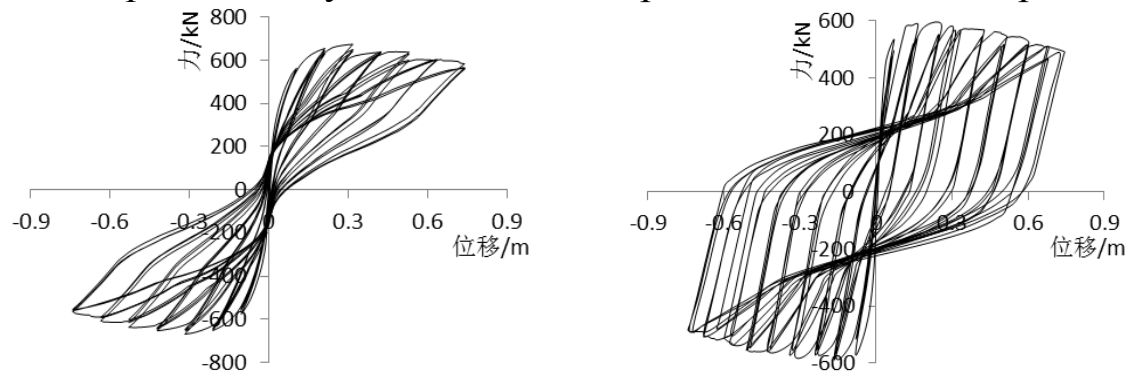

(a)hysteretic curve of p-y curve method (b)hysteretic curve of equivalent embedded method

Fig.7. Comparison of hysteresis curves of pile with embedded depth of $23 \mathrm{~m}$

According to different embedded depths of pile foundation, the cumulative hysteretic energy dissipation and the characteristic displacement calculated by $p-y$ curve method and equivalent embedded method respectively are shown in table 2 . It can be seen from the table that, when the embedded depths of pile were same, the cumulative hysteretic energy dissipation that obtained by equivalent embedded method was far greater than that by p-y curve method; with the increase of the embedded depth of pile foundation, the energy dissipation capacity of pile foundation obtained by the two methods were both enhanced. When the embedded depth of pile foundation were $14 \mathrm{~m}, 17 \mathrm{~m}, 20 \mathrm{~m}$, $23 \mathrm{~m}$ respectively, the cumulative hysteretic energy dissipation obtained by equivalent embedded method was about 2.2 2.5 times of that by p-y curve method.

Tab.2. Characteristic displacement and ductility coefficient of pile foundation

\begin{tabular}{|c|c|c|c|c|c|c|c|c|}
\hline \multirow{3}{*}{ Deformation Index } & \multicolumn{8}{|c|}{ Embedded Depth of Pile Foundation } \\
\hline & \multicolumn{2}{|c|}{$14 \mathrm{~m}$} & \multicolumn{2}{|c|}{$17 \mathrm{~m}$} & \multicolumn{2}{|c|}{$20 \mathrm{~m}$} & \multicolumn{2}{|c|}{$23 \mathrm{~m}$} \\
\hline & Method1 & Method2 & Method1 & Method2 & Method1 & Method2 & Method1 & Method2 \\
\hline Yield Displacement(m) & 0.314 & 0.330 & 0.211 & 0.236 & 0.140 & 0.144 & 0.102 & 0.086 \\
\hline Ultimate Displacement(m) & 1.237 & 1.782 & 1.150 & 1.519 & 0.979 & 1.074 & 0.726 & 0.705 \\
\hline $\begin{array}{c}\text { Cumulative Hysteretic } \\
\text { Energy Dissipation(kN.m) }\end{array}$ & 1234 & 3095 & 1678 & 4222 & 2016 & 4835 & 2644 & 5810 \\
\hline $\begin{array}{c}\text { Displacement Ductility } \\
\text { Factor }\end{array}$ & 3.939 & 5.400 & 5.450 & 6.436 & 6.993 & 7.458 & 7.118 & 8.198 \\
\hline
\end{tabular}

Notes: Method1: P-y curve method; Method2: Equivalent embedding method

As is shown in Table 2, with the increase of the embedded depth of pile foundation, the yield displacement and the ultimate displacement obtained by the two methods were both reduced, while 
the displacement ductility factors were both increased; For the same depth, the displacement ductility factor obtained by equivalent embedded method was greater than that by $p$-y curve method. When the embedded depth of pile foundation were $14 \mathrm{~m}, 17 \mathrm{~m}, 20 \mathrm{~m}, 23 \mathrm{~m}$, the displacement ductility factors obtained by equivalent embedded method were increased by $36.9 \%, 18.1 \%, 6.5 \%, 15.3 \%$ respectively than those by $\mathrm{p}-\mathrm{y}$ curve method, the displacement ductility factor by equivalent embedded method was about 1.1 1.4 times of that by p-y curve method.

\section{Conclusion}

In this paper, the equivalent embedded model and the p-y curve soil spring were used to simulate the pile-soil interaction, and the relevant seismic performance index of PHC pipe piles was obtained by applying cyclic load to them. The main conclusions are as follows:

(1) Compared with that by p-y curve method, the hysteresis curve obtained by equivalent embedded method was fuller, and the cumulative hysteretic energy dissipation by the two methods differenced a lot: with the increase of the embedded depth of pile foundation, the cumulative hysteretic energy dissipation index obtained by equivalent embedded model was about 2.2 2.5 times of that by p-y curve model.

(2) The pile displacement ductility factors by the two methods were both increased with the increase of the embedded depth of pile foundation; with different depths, the displacement ductility factor obtained by equivalent embedded method was about 1.1 1.4 times of that by p-y curve method.

(3) With the increase of the embedded depth of pile foundation, the yield strength and the ultimate strength of pile foundation obtained by the two methods were both increased. Under the same embedded depth of pile foundation, the yield strength and the ultimate strength of pile foundation obtained by $\mathrm{p}-\mathrm{y}$ curve method were higher, while the differences were small.

It can be indicated that in the study of seismic performance of PHC pipe pile, the seismic performance index obtained by equivalent embedded model differs a lot to that by p-y curve model, thus it is necessary to adopt more reasonable pile-soil interaction model for the analysis of seismic performance indexes of PHC pipe piles.

\section{Acknowledgements}

The work described in this paper was supported by the Natural Science Foundation of Jiangsu Province (BK20151498).

\section{References}

[1] JTS167-4-2012, Code for pile foundation of harbor engineering[s]. Beijing: China Communication Press, 2012. ( in Chinese)

[2] GB13476-2009, Pretensioned spun concrete piles[s]. Beijing: Standards Press of China, 2010. ( in Chinese)

[3] Department of civil engineering, Tsinghua University. User Manual of PQ-Fiber v3.0 [P]. (in Chinese)

[4] API RP 2A-WSD-2005, Recommended practice for planning, designing and constructing fixed offshore platforms-working stress design [S].

[5] Port of Long Beach, Wharf Design Criteria [S]. Version3.0. Long Beach: CA, 2012.

[6] 10G409, prestressed concrete pipe pile, Beijing: China Planning Press, 2010. (in Chinese)

[7] JGJ 101-1996, Specificating of testing methods for earthquake resistant building[S]. Beijing: China Architecture \& Building Press, 1997. (in Chinese) 